\title{
Disgust Sensitivity and Moral Judgments of Purity: The Role of Transgression Weirdness
}

\author{
Fieke M. A. Wagemans ${ }^{1}$ \\ Mark J. Brandt ${ }^{1}$ \\ Marcel Zeelenberg ${ }^{1,2}$ \\ ${ }^{1}$ Tilburg University, ${ }^{2}$ Vrije Universiteit Amsterdam
}

Correspondence regarding this manuscript should be addressed to

F.M.A.Wagemans@tilburguniversity.edu

Draft Date: 22 August 2017

You have our permission to cite this paper. Please do not quote the paper directly as changes may occur. This is a pre-print of a submitted paper. Supplemental materials at the Open Science Framework will be available upon acceptance of the paper. 


\begin{abstract}
Disgust sensitivity is more strongly related to moral judgments in the purity domain than to moral judgments in other moral domains. While this finding highlights the distinctiveness of moral domains, anti-modularity accounts suggest that the relationship is caused by the relative weirdness of purity transgressions and come to the conclusion that moral domains do not represent distinct mechanisms. In two studies (total $N=2,307$ ), we test whether transgression weirdness accounts for disgust sensitivity's stronger association with moral judgments of the purity as compared to other moral domains, but find little evidence for this claim. The relationship between disgust sensitivity and moral judgments of purity even remains when taking into account both (perceived) weirdness and (perceived) harmfulness of moral transgressions. These studies show that transgression weirdness and harmfulness cannot explain the disgust sensitivity-purity link, contradicting predictions following from popular anti-modularity accounts.
\end{abstract}

Keywords: morality, disgust, purity, weirdness, harm 


\section{Disgust Sensitivity and Moral Judgments of Purity: The Role of Transgression Weirdness}

Are moral domains distinct entities? Some perspectives argue for distinct moral domains with different causes and consequences (modularity accounts; e.g., Graham et al., 2013), whereas other perspectives argue for a single moral domain associated with perceived harm (antimodularity accounts; e.g., Schein \& Gray, in press). One relevant finding to this debate is the consistently stronger relationship between trait disgust sensitivity and moral judgments of purity transgressions compared to moral judgments of transgressions of other types of moral domains (Horberg, Oveis, Keltner, \& Cohen, 2009; Wagemans, Brandt, \& Zeelenberg, in press). The advocates for modularity accounts interpret this finding as evidence for the distinctiveness of moral domains (Graham et al., in press) because it highlights that purity moral judgments have a distinct predictor. However, this distinct relationship might not be caused by differences in moral content per se, but by other characteristics of purity transgressions. More specifically, some propose that a sampling bias of the moral domain has resulted in purity transgressions that are substantially weirder than other types of moral transgressions (Gray \& Keeney, 2015), which might explain the stronger relationship between disgust sensitivity and moral judgments of purity versus other moral domains. We test this hypothesis.

\section{The Debate}

A substantial number of studies have demonstrated that those scoring higher on trait disgust sensitivity show enhanced moral condemnation of issues such as abortion, non-traditional sexual practices, gay marriage, and homosexuality in general (Crawford, Inbar, \& Maloney, 2014; Inbar, Pizarro, \& Bloom, 2009; Inbar, Pizarro, Knobe, \& Bloom, 2009; Jarudi, 2009; Olatunji, 2008; Smith, Oxley, Hibbing, Alford, \& Hibbing, 2011). The association appears to be domain-specific: Disgust sensitivity has a consistently stronger relationship with moral 
judgments of purity issues than with moral judgments of any other moral domain, including care, fairness, authority, loyalty, and liberty domains (Horberg et al., 2009; Wagemans et al., in press).

The consistently stronger association between disgust sensitivity and purity judgments provides evidence for the distinctiveness of moral domains as proposed by theories advocating moral modularity, such as Moral Foundations Theory (Graham et al., in press; Horberg et al., 2009). Importantly, these modularity accounts are based on the notion that moral domains are meaningfully distinct categories that each have their own psychological processes and causal factors, such as personality characteristics that make individuals more sensitive to a specific moral domain (Graham et al., 2013). For the moral domain of purity this appears to be disgust sensitivity. The idea is that disgust developed from a purely disease avoidance emotion to an emotion that is also triggered by perceptions of immorality (Curtis \& Biran 2001; Rozin, Haidt, \& McCauley, 2000; Tybur, Lieberman, Kurzban, \& DeScioli, 2013). The joint association between disgust and the purity domain specifically likely results from the shared pathogen avoidance process thought to underpin the evolutionary origins of both feelings of disgust and moral purity (Haidt, 2012; Inbar \& Pizarro, 2014).

It is possible, however, to interpret the link between disgust sensitivity and purity judgments from another perspective. That is, the link between disgust sensitivity and purity judgments might result from a sampling bias of the moral domain (Chakroff \& Young, 2015; Gray \& Keeney, 2015). The idea here is that a bias in the selection of purity transgressions resulted in scenarios that are substantially weirder than scenarios representing other moral domains. In line with this reasoning, Gray and Keeney (2015) show that classic purity transgressions (e.g., "someone cooks and eats their dog, after it dies of natural causes") are perceived to be weirder than transgressions of the care domain (e.g., "someone kicks a dog in the 
head, hard"; Graham, Haidt, \& Nosek, 2009). Both are immoral, both involve dogs, but one is perceived to be considerable weirder.

This finding is interpreted as being consistent with anti-modularity accounts because it suggests that weirdness, and not some distinct moral mechanism, might be responsible for the disgust sensitivity-purity link. It is possible that both disgust sensitivity and moral judgments of purity are tapping into a general sensitivity towards weird or bizarre situations, and that scenario weirdness therefore accounts for the stronger association between disgust sensitivity and moral judgments of purity transgressions. If this hypothesis is supported, it would challenge not only the existence of a purity domain that is meaningfully distinguishable from other moral domains, but it would also question the validity of Moral Foundations Theory, one of the most prominent theories in moral psychology.

\section{The Current Studies}

Despite the theoretical importance of the weirdness confound, there is no satisfactory empirical study testing the possibility. Other studies have examined weirdness and disgust (Schein, Ritter, \& Gray, 2016; Study 3), but they did not test if weirdness accounts for the differential relationships across domains. That is, they did not account for the finding that most clearly separates the modularity accounts from the anti-modularity accounts. In the current paper, we will directly test whether transgression weirdness can explain the stronger relationship between disgust sensitivity and moral judgments of the purity domain compared to other moral domains.

\section{Study 1}

We first test whether we replicate the finding that purity transgressions are perceived to be weirder than transgressions from other moral domains. Next, we test whether this weirdness 
moderates the relationship between disgust sensitivity and moral judgments over and above the moderating effect of moral domain, such that disgust sensitivity has a stronger relationship to moral judgments of transgressions that are perceived to be weirder. For this, we ask one sample of participants to rate how weird they find a number of standardized moral judgments (Clifford, Iyengar, Cabeza, \& Sinnott-Armstrong, 2015) and combine these weirdness ratings with published (Wagemans et al., in press) and unpublished existing datasets on the relationship between disgust sensitivity and moral judgments ${ }^{1}$. In addition, we control for transgression harmfulness because it is suggested as an important factor underlying moral judgments (Gray \& Schein, 2012).

\section{Method}

We aggregated data from studies that include a measure of disgust sensitivity and moral judgments from the Moral Foundations Vignettes (Clifford et al., 2015). We chose this set of moral judgments as it is a well-validated and standardized set of moral judgments based on Moral Foundations Theory (see Clifford et al., 2015 for a description of the validation process), which includes moral transgressions of six moral domains: Purity, care, authority, fairness, loyalty, and liberty. In order to make comparisons between moral domains, datasets were only included when they measured moral judgments of the purity domain and at least one other moral domain. Because none of the existing datasets included measures of transgression weirdness or transgression harmfulness, a new sample was collected to measure these aspects. The existing and new datasets were then combined by matching moral transgressions in the existing datasets with the average weirdness and harmfulness score per moral transgression from the new dataset.

\footnotetext{
${ }^{1}$ The exact materials that were used in these studies and the relevant datasets can be found in the Supplemental Materials at the Open Science Framework.
} 
New Data Participants. To get reliable estimates of a transgression's weirdness and harmfulness, we aimed to collect ratings of at least 75 participants for each rating type. In the end, 151 participants were recruited via Amazon's Mechanical Turk (78 males, 73 females, $M_{\text {age }}$ $=34.30, S D=10.37$ ) and completed our study in return for a financial reward.

New Data Materials. Moral transgressions were taken from the Moral Foundations Vignettes (Clifford et al., 2015). A total of 60 transgressions were used; ten from each moral domain (i.e., purity, care, authority, fairness, loyalty, and liberty). Example items are "You see an employee at a morgue eating his pepperoni pizza off of a dead body" (purity domain) and "You see a woman spanking her child with a spatula for getting bad grades in school" (care domain). To allow matching of the new dataset with the existing datasets, the moral transgressions used in this new study include all moral transgressions that were used in the existing datasets.

Participants were randomly assigned to rate the weirdness or the harmfulness of moral transgressions. Depending on the task, participants indicated for each moral transgression how weird (i.e., unusual, bizarre, odd) they found the situation on a scale ranging from $1=$ 'Not at all weird' to $7=$ 'Extremely weird', or how harmful they found the situation on a scale ranging from $1=$ 'Not at all harmful' to $7=$ 'Extremely harmful'. Intraclass correlation coefficients (ICC) for these sets were calculated using the "icc" function in the "irr" package of R (Gamer, Lemon, Fellows, \& Sing, 2012). The model was set to be "twoway" and the type of ICC was set to “consistency”. ICC's for, respectively, weirdness and harmfulness ratings were .37 (95\% CI $[0.30,0.47])$ and $.19(95 \% \mathrm{CI}[0.14,0.26])$. All moral transgressions were presented in a random order to each participant. 
Existing Datasets. The new data was combined with six published datasets (Wagemans et al., in press) and three unpublished datasets from our lab (total $N=2,008$ ). As described above, in each dataset, moral judgments were measured with items from the Moral Foundations Vignettes (Clifford et al., 2015), but the number of items and moral domains measured differs per dataset (see Table 1). In seven of the datasets, disgust sensitivity was measured with the 27item Disgust Sensitivity Scale-Revised (DS-R; Haidt, McCauley, \& Rozin., 1994, modified by Olatunji et al., 2007), in one dataset with the 30-item London Disgust Scale (Curtis, 2013), and in one dataset with the 21-item Three Domain Disgust Scale (Tybur, Lieberman, \& Griskevicius, 2009). This last disgust sensitivity scale has three subscales; pathogen, sexual, and moral disgust. For our study, we excluded the moral disgust subscale because this subscale likely has a different relationship with purity transgressions than the pathogen and sexual disgust subscales, as the items in the scale are conceptually close to moral transgressions of fairness and care. The other two subscales, pathogen and sexual disgust, were combined into one disgust sensitivity variable. An overview of the datasets and the materials that were used in each dataset can be found in Table 1.

\section{Results}

Data Analytic Strategy. All samples were analyzed together. Linear mixed-effects models were used to estimate the effects of disgust sensitivity, moral domain, weirdness, and harmfulness on moral judgments while taking into account random variance (and nesting) of participants, moral transgressions, and samples. The analyses were conducted using the "Imer" function in the "lme4" package of R (Bates, Mächler, Bolker, \& Walker, 2015). The "lmerTest" package was used to obtain $p$-values for regression coefficients (Kuznetsova, Brockhoff, \& Christensen, 2013) and the "confint" function in the "stats" package was used to obtain 
Table 1

Overview of existing datasets and their materials used in Study 1.

\begin{tabular}{|c|c|c|c|c|c|c|c|c|}
\hline Samples & $N$ & $\begin{array}{c}\text { DS scale } \\
(\alpha)\end{array}$ & $\begin{array}{c}\text { Purity } \\
\text { No. of items }(\alpha)\end{array}$ & $\begin{array}{c}\text { Care } \\
\text { No. of items }(\alpha)\end{array}$ & $\begin{array}{c}\text { Fairness } \\
\text { No. of items }(\alpha)\end{array}$ & $\begin{array}{c}\text { Authority } \\
\text { No. of items }(\alpha)\end{array}$ & $\begin{array}{c}\text { Loyalty } \\
\text { No. of items }(\alpha)\end{array}$ & $\begin{array}{c}\text { Liberty } \\
\text { No. of items }(\alpha)\end{array}$ \\
\hline Dataset 1 & 80 & DS-R (.85) & $2\left(.20_{a}\right)$ & $2\left(.13_{a}\right)$ & $2\left(.18_{a}\right)$ & $2\left(.42_{a}\right)$ & & \\
\hline Dataset 2 & 221 & DS-R (.88) & $3(.63)$ & $3(.43)$ & $2\left(.25_{\mathrm{a}}\right)$ & $2(.44 a)$ & & \\
\hline Dataset 3 & 204 & DS-R (.84) & $3(.63)$ & $3(.57)$ & $2\left(.47_{a}\right)$ & $2\left(.30_{\mathrm{a}}\right)$ & & \\
\hline Dataset 4 & 148 & DS-R (.84) & $4(.63)$ & $2\left(.08_{a}\right)$ & $2\left(.25_{a}\right)$ & & & \\
\hline Dataset 5 & 451 & DS-R (.87) & $10(.91)$ & $10(.90)$ & $10(.90)$ & $10(.92)$ & $10(.92)$ & $10(.90)$ \\
\hline Dataset 6 & 304 & DS-R $(.89)_{b}$ & $10(.93)$ & $10(.91)$ & $10(.90)$ & $10(.94)$ & $10(.94)$ & $10(.91)$ \\
\hline Dataset 7 & 201 & DS-R (.92) & $10(.90)$ & $10(.90)$ & & & & \\
\hline Dataset 8 & 199 & LD (.94) & $10(.87)$ & $10(.91)$ & & & & \\
\hline Dataset 9 & 200 & TDD (.88) & $10(.87)$ & $10(.90)$ & & & & \\
\hline
\end{tabular}

Note: DS-R = Disgust Sensitivity Scale - Revised; LD = London Disgust Scale; TDD = Three Domain Disgust Scale (pathogen and sexual subscales). Table includes the disgust sensitivity scale (DS) used, the number of moral judgments per domain, and reliabilities $(\alpha)$ of all scales per sample. Reliability estimates with an a indicate correlations. $\mathrm{b}_{\mathrm{a}}$ In this dataset, seven DS-R items were accidentally excluded. Analyses were conducted with the 19 remaining items. 
confidence intervals for all effects using Monte Carlo simulations (drawing 1000 bootstrap samples; R Core Team, 2017). Because not all disgust sensitivity scales were measured on the same response scale, disgust sensitivity scores were mean centered and standardized within each dataset (generating z-scores using the "scale" function in the "base" package of R; R Core Team, 2017). To improve comparability of predictors, also transgression weirdness and transgression harmfulness ratings were mean centered and standardized by generating z-scores.

Before testing the moderating effect of transgression weirdness, we tested whether purity transgressions are indeed perceived to be weirder than transgressions of other moral domains. Replicating Gray and Keeney (2015), we found that purity transgressions are perceived to be significantly weirder $(M=5.90, S D=1.56)$ than transgressions of all other moral domains (all means $<4.73$, SD's $<1.93$, absolute values of all $t$ 's $>3.88, p$ 's $<.001$; see Supplemental Materials). ${ }^{2}$

Moral Domain and Weirdness as Moderators. Prior work found that disgust sensitivity is more strongly associated with moral judgments in the purity domain compared to other moral domains. To re-test this, we used disgust sensitivity, moral domain $(0=$ non-purity, $1=$ purity $)$, and their interaction to predict moral judgments. There was a significant main effect of disgust sensitivity $(b=0.32, S E=0.01, t[49360]=34.44, p<.001,95 \%$ CI $[0.30,0.34])$ and moral domain $(b=0.86, S E=0.29, t[59]=2.98, p=.004,95 \%$ CI $[0.29,1.42])$. Replicating past work, there was a significant interaction between disgust sensitivity and moral domain $(b=0.28, S E=$

\footnotetext{
${ }^{2}$ Purity transgressions were perceived to be equally harmful as transgressions of the care, fairness, and liberty domains (absolute values of all $t$ 's $<0.58, p$ 's $>.56$ ), but were perceived as significantly more harmful than transgressions of the authority and loyalty domains (absolute values of both $t$ 's $>3.49, p$ 's $<.001$; see Supplemental Materials).
} 
$0.02, t[24077]=16.24, p<.001,95 \% \mathrm{CI}[0.25,0.31])$, indicating a stronger association between disgust sensitivity and moral judgments of purity as compared to non-purity domains (see Figure 1 , left panel). ${ }^{3}$

To test if transgression weirdness accounts for this interaction, we tested a second model in which transgression weirdness and its interaction with disgust sensitivity were added. There was no main effect of transgression weirdness $(b=-0.06, S E=0.15, t[57]=-0.36, p=.72,95 \%$ CI $[-0.38,0.25])$ and also the interaction between disgust sensitivity and transgression weirdness was not significant $(b=-0.01, S E=0.01, t[3890]=-0.90, p=.37,95 \%$ CI $[-0.03,0.01])$. The interaction between disgust sensitivity and moral domain, however, remained $(b=0.30, S E=$ $0.03, t[8666]=11.74, p<.001,95 \% \mathrm{CI}[0.25,0.34])$, showing that transgression weirdness cannot account for the domain-specific relationship between disgust sensitivity and moral judgments of purity.

Finally, we tested whether controlling for transgression harmfulness and its interaction with disgust sensitivity affects our findings by adding these terms to a third model. While there was a main effect of transgression harmfulness $(b=0.72, S E=0.06, t[60]=11.98, p<.001,95 \%$ CI $[0.60,0.84])$ and a significant interaction effect of disgust sensitivity and transgression harmfulness $(b=-0.07, S E=0.01, t[11030]=-8.47, p<.001,95 \%$ CI $[-0.08,-0.05])$, the interaction between disgust sensitivity and moral domain still remained $(b=0.27, S E=0.03$, $t[8601]=10.66, p<.001,95 \%$ CI [0.22, 0.32]; see Figure 1, right panel). We replicated and reproduced prior work and showed that neither weirdness nor harmfulness of a moral

\footnotetext{
${ }^{3}$ Much of this data was previously published (Wagemans et al., in press) and found the same results. This analysis merely shows that the effect still holds after including new data using various measures of disgust sensitivity and with a different (but conceptually similar) data analytic strategy, chosen to more easily incorporate weirdness.
} 
transgression can account for the domain-specific relationship between disgust sensitivity and moral judgments of purity. Notably, the effect size of the interaction between disgust sensitivity and moral domain barely changed across models. This can be seen by comparing the remarkably similar panels in Figure 1.
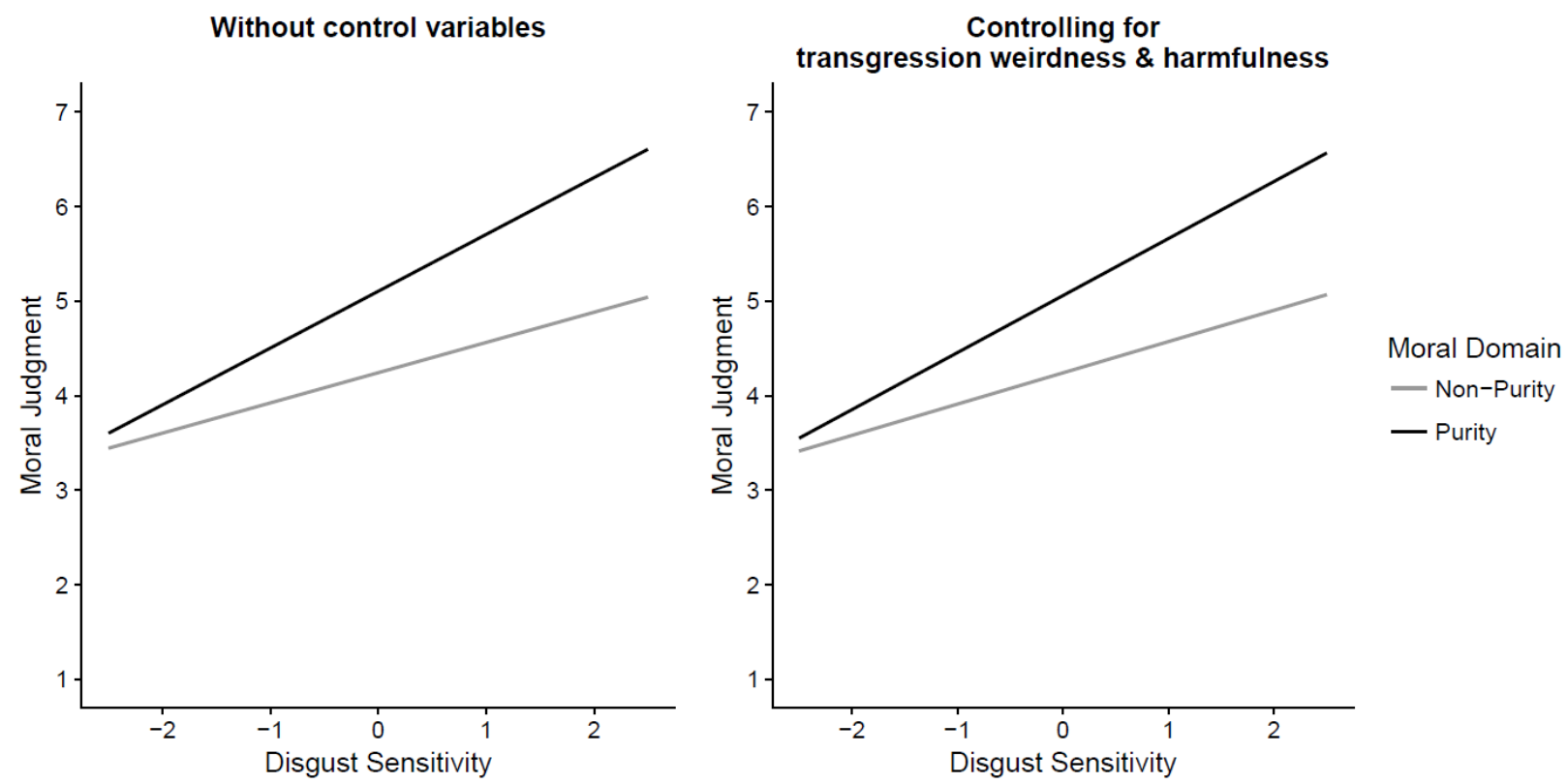

Figure 1. The interaction effect of disgust sensitivity (standardized) and moral domain (purity vs non-purity transgressions) on moral judgments (Study 1). The left panel is the initial disgust sensitivity moral domain interaction $(b=0.28, S E=0.02, p<.001)$. The right panel is the disgust sensitivity moral domain interaction controlling for transgression weirdness, transgression harmfulness, and interactions between these variables and disgust sensitivity $(b=$ $0.27, S E=0.03, p<.001)$.

\section{Discussion}

In the first study, we tested whether transgression weirdness can account for the 
moderating effect of moral domain on the relationship between disgust sensitivity and moral judgments. It cannot.

The methods of the first study made it possible to test the influence of weirdness in a large sample, but it also has a shortcoming. We calculated average weirdness scores for each moral transgression and subsequently matched these scores with existing data on the relationship between disgust sensitivity and moral judgments. While this set-up assumes transgression weirdness to be a constant factor across participants, this assumption might be faulty. For instance, the relatively low intraclass correlation coefficients of transgression weirdness and transgression harmfulness found in Study 1 suggest that individuals do not fully agree on what is or is not weird. It is possible that more disgust sensitive individuals judge moral transgressions of the purity domain to be more immoral because they perceive them to be more deviant from what is normal (i.e., weird). The idea is that weirdness mediates the relationship between disgust sensitivity and moral judgments of the purity domain, such that more disgust sensitive people perceive purity transgressions to be weirder than less disgust sensitive people and, as a result, judge these transgressions as more immoral. In Study 2, we tested this mediation hypothesis by obtaining disgust sensitivity scores and ratings of immorality and weirdness all from the same participants. We also tested the potential of perceived harmfulness as a mediator in our model (cf. Schein et al., 2016).

\section{Study 2}

\section{Method}

Participants. Students could participate in our lab study for one week (usually yielding between 100 and 150 participants). In the end, 148 Dutch students (33 males, 115 females, $M_{\text {age }}$ $=20.16, S D=2.85)$ participated in our study in return for course credit. Because a power 
analysis for our multilevel mediation model would likely be inaccurate as it requires a priori information of various unknown factors (e.g., intra-class correlation coefficients and estimations of multiple path coefficients), we used two rough estimations of power. First, using G*Power (Faul, Erdfelder, Lang, \& Buchner, 2007), we calculated the size of the difference in slopes (i.e., difference between disgust sensitivity's relationship to moral judgments of the purity and nonpurity domains) this sample allows us to detect given $80 \%$ power. This resulted in a difference in slopes of .232 and higher. As a second estimation of power, we used Preacher, Rucker, and Hayes' (2007) power estimates for single-level moderated mediation analysis, which shows that a sample size of 100 is sufficient to detect medium effects with close to $95 \%$ power.

Materials. To help avoid consistency effects, our study was divided into two parts that were separated by an unrelated study on attitudes towards social groups. In the first part of our study, participants rated a total of 48 moral transgressions that were taken from the same set of moral transgressions as in Study 1 (i.e., Moral Foundations Vignettes; Clifford et al., 2015). These 48 moral transgressions were equally divided over six moral domains: Purity, care, authority, fairness, loyalty, and liberty. For each transgression, participants used three items to indicate to what degree they found the situation immoral ("I find this immoral"), weird ("I find this weird [unusual, bizarre, odd]"), and harmful ("I find this harmful") on a scale ranging from 1 $=$ 'Not at all" to $7=$ "Very much". All moral transgressions were presented in a random order to each participant.

Participants then participated in the unrelated study before continuing with the second part of our study in which participants filled out the 27-item Disgust Sensitivity Scale revised (Haidt et al., 1994; modified by Olatunji et al., 2007; $\alpha=.85$ ). This is the same disgust sensitivity scale used in many of the samples in Study 1. The first 14 items are answered on a 5-point scale 
ranging from $1=$ 'Strongly disagree (very untrue about me)' to $5=$ 'Strongly agree (very true about me)'. An example item is "It bothers me to hear someone clear a throat full of mucus". The remaining 13 items are answered on a 5-point scale ranging from $1=$ 'Not disgusting at all' to 5 $=$ 'Extremely disgusting'. An example item is "While you are walking through a tunnel under a railroad track, you smell urine". The scale includes two filler items that are excluded from all analyses.

\section{Results}

Data Analytic Strategy. As in Study 1, linear mixed-effects models were used to estimate the effects of disgust sensitivity, moral domain, perceived weirdness, and perceived harmfulness on moral judgments while taking into account random variance (and nesting) of participants and moral transgressions. Regression coefficients, $p$-values, and confidence intervals were obtained in the same manner as in Study 1. Following recommendations by Zhang, Zyphur, and Preacher (2009), disgust sensitivity (i.e., Level-2 predictor) was grand-mean centered by subtracting the overall mean from each individual's disgust sensitivity score, while perceived weirdness and harmfulness (i.e., Level-1 predictors) were cluster-mean centered by subtracting each individual's mean weirdness or harmfulness score from the weirdness or harmfulness ratings. Each individual's mean weirdness or harmfulness score (i.e., Level-2 predictors) was grand-mean centered by subtracting the overall weirdness or harmfulness mean from each individual's mean weirdness or harmfulness score. All models using perceived weirdness and/or harmfulness as predictors include both the Level 1 and Level 2 versions of the variables, but only the effects of the Level 2 variables are reported as these are relevant to our predictions (also see Zhang et al., 2009; see Supplemental Materials for full model results). To test for multilevel moderated multiple mediation in a 2-1-1 model, we followed the steps described by Zhang and 
colleagues (2009) for multilevel mediation and, following the hypotheses, test the moderating effect of moral domain in steps 1 and 2.

Step 1. Disgust Sensitivity and Moral Judgments. First, we tested whether disgust sensitivity is a predictor of moral judgments. A positive relationship was found $(b=0.27, S E=$ $0.08, t(146)=3.35, p=.001,95 \%$ CI $[0.10,0.42])$, showing that higher scores on disgust sensitivity are associated with harsher moral judgments across domains. To test for the moderating effect of moral domain, the model was extended with moral domain (non-purity $=0$, purity $=1$ ) and its interaction with disgust sensitivity as predictors. In line with Study 1 and previous findings (Wagemans et al., in press), moral domain moderated the effect of disgust sensitivity on moral judgments $(b=0.71, S E=0.13, t(146)=5.44, p<.001,95 \%$ CI $[0.45$, 0.95]), such that disgust sensitivity was more strongly related to moral judgments of purity $(b=$ $0.86, S E=0.14, t(146)=6.10, p<.001,95 \% \mathrm{CI}[0.61,1.14])$ than to moral judgments of nonpurity domains $(b=0.15, S E=0.08, t(146)=1.87, p=.06,95 \%$ CI $[-0.01,0.33]$; see Figure 2).

Step 2A. Disgust Sensitivity and Perceived Weirdness. We then tested whether disgust sensitivity is a predictor of the first potential mediator, perceived weirdness. A positive relationship was found $(b=0.22, S E=0.08, t(146)=2.62, p=.01,95 \%$ CI $[0.06,0.39])$, showing that higher disgust sensitivity scores are associated with higher perceptions of weirdness across all moral domains. To test the potential of perceived weirdness as a mediator of the relationship between disgust sensitivity and moral judgments of the purity domain specifically, the moderating effect of moral domain was again tested by including moral domain and its interaction with disgust sensitivity in the model. No interaction effect of moral domain and disgust sensitivity on perceived weirdness was found $(b=-0.02, S E=0.11, t(189.68)=-0.22, p$ $=.82,95 \% \mathrm{CI}[-0.21,0.17])$, showing that perceived weirdness cannot account for the stronger 
association between disgust sensitivity and moral judgments of purity transgressions as compared to moral judgments of non-purity transgressions. It is therefore no longer considered as a potential mediator of the disgust sensitivity-domain interaction effect. To be conservative, we controlled for perceived weirdness in all subsequent models with moral judgments as the outcome variable (see Figure 2 and the Supplemental Materials).

Step 2B. Disgust Sensitivity and Perceived Harmfulness. We then tested whether disgust sensitivity was related to the second potential mediator, perceived harmfulness. A positive relationship was found $(b=0.30, S E=0.10, t(146)=2.88, p=.005,95 \%$ CI $[0.08$, 0.50]), showing that higher disgust sensitivity scores are associated with higher perceptions of harmfulness across all moral domains. To test whether perceived harmfulness can account for the relationship between disgust sensitivity and moral judgments of the purity domain specifically, the moderating effect of moral domain was again tested by including moral domain and its interaction with disgust sensitivity in the model. This revealed a significant interaction effect of disgust sensitivity and moral domain on perceived harmfulness $(b=0.73, S E=0.14, t(146)=$ $5.03, p<.001,95 \% \mathrm{CI}[0.45,1.01])$. In line with the idea of perceived harmfulness as a mediator of the disgust sensitivity-purity link specifically, disgust sensitivity relates to perceived harmfulness of purity transgressions $(b=0.90, S E=0.16, t(146)=5.52, p<.001,95 \%$ CI $[0.58$, 1.20]) but not to perceived harmfulness of non-purity transgressions $(b=0.18, S E=0.11, t(146)$ $=1.69, p=.09,95 \%$ CI $[-0.03,0.38])$; see Figure 2).

Step 3. Perceived Harmfulness and Moral Judgments. Because moral domain moderates the paths of disgust sensitivity to both moral judgments and perceived harmfulness, we further test the potential for perceived harmfulness as a mediator for each level of moral domain (purity vs non-purity) separately. A model including disgust sensitivity, perceived 
harmfulness, and perceived weirdness as predictors and moral judgments as the outcome variable was fitted to the data on purity transgressions and the data on non-purity transgressions. Perceived harmfulness related positively to both purity $(b=0.47, S E=0.07, t(180.12)=6.53, p$ $<.001,95 \% \mathrm{CI}[0.33,0.62])$ and non-purity moral judgments $(b=0.31, S E=0.05, t(144.97)=$ $5.86, p<.001,95 \% \mathrm{CI}[]$,$) , showing that transgressions that are perceived to be more harmful$ are also considered to be more immoral (see Figure 2).

Indirect and Direct Effects. Indirect and direct effects were calculated for each level of moral domain (purity vs non-purity) separately. In line with the idea of perceived harmfulness as a mediator of the disgust sensitivity-purity link specifically, perceived harmfulness did not mediate the relationship between disgust sensitivity and moral judgments for non-purity transgressions (indirect effect: $0.06, S E=0.04, z=1.58, p=.11$ ), but it did do so for purity transgressions (indirect effect: 0.42, SE $=0.10, z=4.31, p<.001$ ). However, even when controlling for perceived weirdness and the mediating effect of perceived harmfulness, the association between disgust sensitivity and moral judgments of purity transgressions remained $(b$ $=0.19, S E=0.08, t(185.76)=2.27, p=.02,95 \% \mathrm{CI}[0.03,0.35])$. Importantly, these findings mean that perceived harmfulness, together with perceived weirdness, can only account for part of the relationship between disgust sensitivity and moral judgments of the purity domain. A graphical representation of this mediation, for purity and non-purity transgressions separately, can be found in Figure 2. 

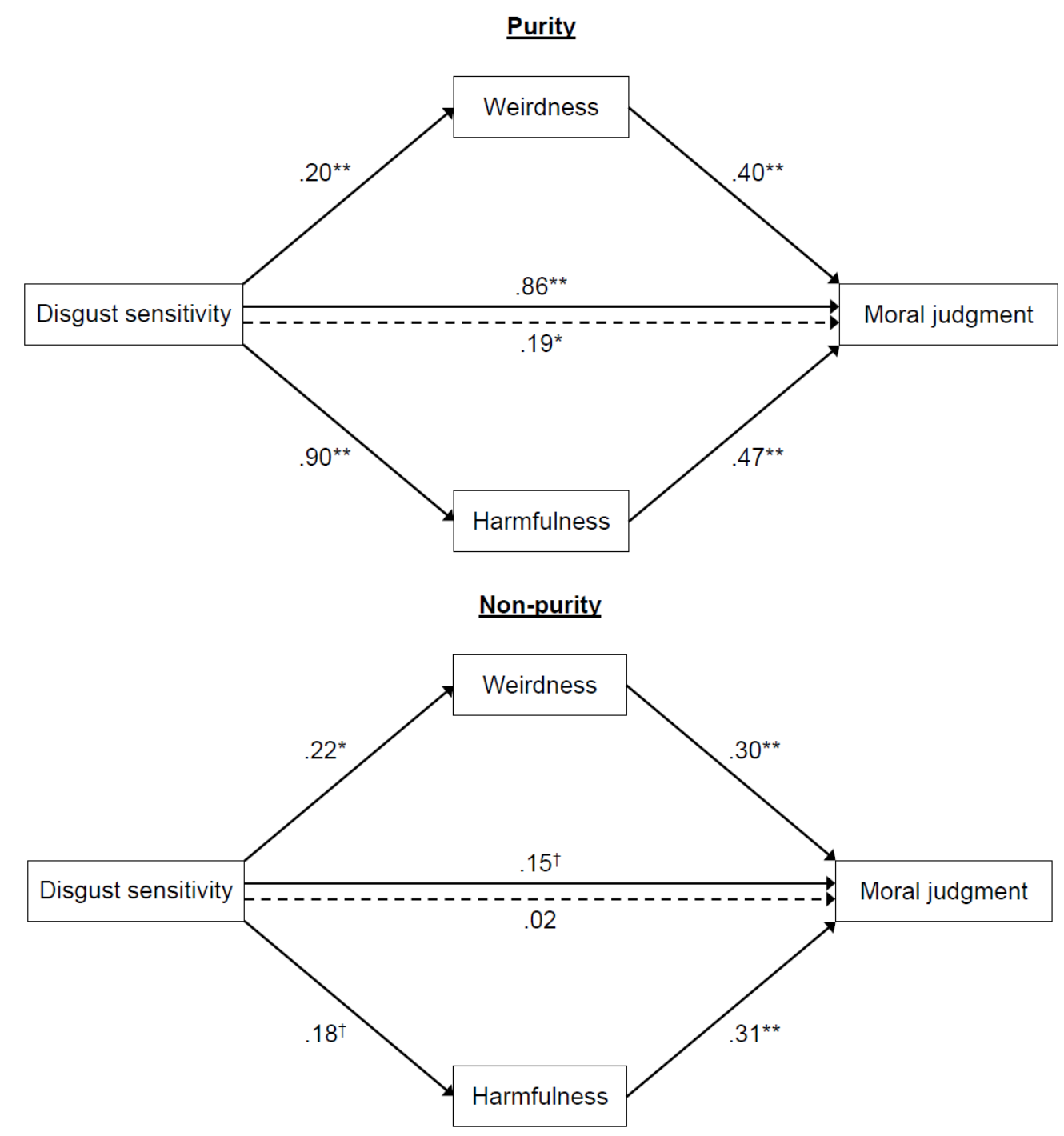

Figure 2. Unstandardized regression coefficients representing the effect of disgust sensitivity on moral judgments, mediated by perceived weirdness and perceived harmfulness of transgressions, for each level of moral domain (i.e., purity vs non-purity transgressions). The dashed line and its regression coefficient represent the direct effect of disgust sensitivity on moral judgments, controlling for perceived weirdness and perceived harmfulness. ${ }^{\dagger} p<.10,{ }^{*} p<.05, * * p<.01$ 


\section{General Discussion}

Moral transgressions of purity are perceived to be weirder than moral transgressions of care (Gray \& Keeney, 2015), but can this weirdness account for the stronger association between disgust sensitivity and moral judgments of purity compared to non-purity transgressions? In two studies, using a total of 2,307 participants, we tested this claim, but found little evidence.

Study 1 shows that transgression weirdness cannot account for the moderating effect of moral domain on the relationship between disgust sensitivity and moral judgments. In Study 2, we further investigate whether perceived weirdness can explain the disgust sensitivity - purity link by testing its potential as a mediator, but find no support for this idea. Together, these studies show that although purity transgressions are indeed weirder than other types of transgressions, this weirdness cannot account for the stronger association between disgust sensitivity and moral judgments of the purity domain.

While we find no evidence for perceived weirdness as an explanation of the stronger relationship between disgust sensitivity and moral judgments of the purity domain, perceived harmfulness appears to be a better candidate. This is in line with predictions following from antimodularity accounts, such as the Theory of Dyadic Morality, stating that moral judgments of all moral domains can be reduced to perceptions of harmfulness (Gray \& Schein, 2012; Schein \& Gray, in press). When it comes to the disgust sensitivity-purity link, it is thought that more disgust sensitive people perceive more harm in transgressions of the purity domain compared to less disgust sensitive people, and subsequently, they show stronger moral condemnation of these transgressions. Importantly, this view of morality, in which perceived harmfulness underlies all moral judgments, also implies that there are no meaningfully distinct modules of morality, thereby contradicting popular theories of moral modularity (e.g., Moral Foundations Theory). 
However, we should also note that the evidence in favor of such an account is limited. If all moral judgments can be reduced to harmfulness perceptions, one would expect that perceived harmfulness fully accounts for any relationship between a personality trait and a specific moral domain. This is not what we find. Although Study 2 shows evidence for perceived harmfulness as a mediator of the disgust sensitivity-purity link, it accounts for only part of the variance. Even when controlling for perceived harmfulness and perceived weirdness, disgust sensitivity's direct relation to moral judgments of purity transgressions remains, suggesting that other factors play an important role in explaining the domain-specific relationship between disgust sensitivity and the purity domain. Interestingly, this means that even when two explanations suggested by antimodularity accounts (i.e., weirdness and harmfulness) are taken into account, the moral domain of purity can be distinguished from other moral domains by its unique association to disgust sensitivity. This supports expectations following from modularity accounts of morality, such as Moral Foundations Theory. 


\section{References}

Bates, D., Mächler, M., Bolker, B., \& Walker, S. (2015). Fitting linear mixed-effects models using lme4. Journal of Statistical Software, 67, 1-48. doi: 10.18637/jss.v067.i01

Cameron, C. D., Lindquist, K. A., \& Gray, K. (2015). A constructionist review of morality and emotions: No evidence for specific correspondences between discrete emotions and moral concerns. Personality and Social Psychology Review, 19, 371-394. doi: $10.1177 / 1088868314566683$

Chakroff, A., \& Young, L. (2015). Harmful situations, impure people: An attribution asymmetry across moral domains. Cognition, 136, 30-37. doi: 10.1016/j.cognition.2014.11.034

Clifford, S., Iyengar, V., Cabeza, R., \& Sinnott-Armstrong, W. (2015). Moral foundations vignettes: A standardized stimulus database of scenarios based on moral foundations theory. Behavior Research Methods, 47, 1178-1198. doi: 10.3758/s13428-014-0551-2

Crawford, J., Inbar, Y., \& Maloney, V. (2014). Disgust sensitivity selectively predicts attitudes towards groups that threaten (or uphold) traditional sexual morality. Personality and Individual Differences, 70, 218-223. doi: 10.1016/j.paid.2014.07.001

Curtis, V. (2013). Don't look, don't touch, the science behind revulsion. Oxford: Oxford University Press.

Curtis V., \& Biran A. (2001). Dirt, disgust, and disease: Is hygiene in our genes? Perspectives in Biology and Medicine, 44, 17-31. doi: 10.1353/pbm.2001.0001 
Faul, F., Erdfelder, E., Lang, A.-G., \& Buchner, A. (2007). G_Power 3: A flexible statistical power analysis program for the social, behavioral, and biomedical sciences. Behavior Research Methods, 39, 175-191. doi:10.3758/BF03193146

Gamer, M., Lemon, J., Fellows, I., \& Sing, P. (2012). irr: Various coefficients of interrater reliability and agreement (Version 0.84) [Computer software]. Retrieved from http://CRAN.R-project.org/package=irr

Graham, J., Haidt, J., Koleva, S., Motyl, M., Iyer, R., Wojcik, S., \& Ditto, P. H. (2013). Moral Foundations Theory: The pragmatic validity of moral pluralism. Advances in Experimental Social Psychology, 47, 55-130. doi: 10.1016/B978-0-12-407236-7.00002-4

Graham, J., Haidt, J., Motyl, M., Meindl, P., Iskiwitch, C., \& Mooijman, M. (in press). On the advantages of moral pluralism over moral monism. In K. Gray \& J. Graham (Eds.), The Atlas of Moral Psychology: Mapping Good and Evil in the Mind. New York: Guilford.

Graham, J., Haidt, J., \& Nosek, B. A. (2009). Liberals and conservatives rely on different sets of moral foundations. Journal of Personality and Social Psychology, 96, 1029-1046. doi: $10.1037 / \mathrm{a} 0015141$

Gray, K., \& Keeney, J. E. (2015). Impure, or just weird? Scenario sampling bias raises questions about the foundation of morality. Social Psychological and Personality Science, 6, 859 -868. doi: $10.1177 / 1948550615592241$

Gray, K. \& Schein, C. (2012). Two minds vs. two philosophies: Mind perception defines morality and dissolves the debate between deontology and utilitarianism. Review of Philosophy and Psychology, 3, 405-423. doi: 10.1007/s13164-012-0112-5 
Haidt, J. (2012). The righteous mind: Why good people are divided by politics and religion. New York: Pantheon.

Haidt, J., McCauley, C., \& Rozin, P. (1994). Individual differences in sensitivity to disgust: A scale sampling seven domains of disgust elicitors. Personality and Individual Differences, 16, 701-713. doi: 10.1016/0191-8869(94)90212-7

Horberg, E. J., Oveis, C., Keltner, D., \& Cohen, A. B. (2009). Disgust and the moralization of purity. Journal of Personality and Social Psychology, 97, 963-976. doi: $10.1037 / \mathrm{a} 0017423$

Inbar, Y. \& Pizarro, D. A. (2014). Pollution and purity in moral and political judgment. In J. C. Wright \& H. Sarkissian (Eds.), Advances in Experimental Moral Psychology: Affect, Character, and Commitments (pp. 111-129). New York: Continuum Press.

Inbar, Y., Pizarro, D. A., \& Bloom, P. (2009). Conservatives are more easily disgusted than liberals. Cognition and Emotion, 23, 714-725. doi: 10.1080/02699930802110007

Inbar, Y., Pizarro, D. A., Knobe, J., \& Bloom, P. (2009). Disgust sensitivity predicts intuitive disapproval of gays. Emotion, 9, 435-439. doi: 10.1037/a0015960.

Jarudi, I. N. (2009). Everyday morality and the status quo: Conservative concerns about moral purity, moral evaluations of everyday objects, and moral objections to performance enhancement. (Doctoral dissertation, Yale University).

Kuznetsova A., Brockhoff P. B., Christensen R. H. B. (2013). lmerTest: Tests in linear mixed effects models (Version 2.0-11) [Computer software]. Retrieved from http://cran.r-project.org/web/packages/lmerTest/ 
Olatunji, B. O. (2008). Disgust, scrupulosity and conservative attitudes about sex: Evidence for a mediational model of homophobia. Journal of Research in Personality, 42, 1364-1369. doi: 10.1016/j.jrp.2008.04.001

Olatunji, B. O., Williams, N. L., Tolin, D. F., Sawchuck, C. N., Abramowitz, J. S., Lohr, J. M., \& Elwood, L. (2007). The Disgust Scale: Item analysis, factor structure, and suggestions for refinement. Psychological Assessment, 19, 281-197. doi: 10.1037/1040-3590.19.3.281

Preacher, K. J., Rucker, D. D., \& Hayes, A. F. (2007). Addressing Moderated Mediation Hypotheses: Theory, Methods, and Prescriptions. Multivariate Behavioral Research, 42, 185-227. doi: 10.1080/00273170701341316

R Core Team (2017). R: A language and environment for statistical computing. R Foundation for Statistical Computing, Vienna, Austria. URL https://www.R-project.org/.

Rozin, P., Haidt, J., \& McCauley, C. R. (2000). Disgust. In M. Lewis \& J. M. Haviland-Jones (Eds.), Handbook of emotions, 2nd Edition (pp. 637-653). New York: Guilford Press.

Schein, C. \& Gray, K. (in press). The Theory of Dyadic Morality: Reinventing moral judgments by redefining harm. Personality and Social Psychology Review. doi: $10.1177 / 1088868317698288$

Schein, C., Ritter, R. S., \& Gray, K. (2016). Harm mediates the disgust-immorality link. Emotion, 16, 862-876. doi: 10.1037/emo0000167

Smith, K. B., Oxley, D., Hibbing, M. V., Alford, J. R., \& Hibbing, J. R. (2011). Disgust sensitivity and the neurophysiology of left-right political orientations. PloS One, 6 , e25552. doi: 10.1371/journal.pone.0025552 
Tybur, J. M., Lieberman, D. L., \& Griskevicius, V. G. (2009). Microbes, mating, and morality: Individual differences in three functional domains of disgust. Journal of Personality and Social Psychology, 29, 103-122. doi: 10.1037/a0015474

Tybur, J. M., Lieberman, D., Kurzban, R., \& DeScioli, P. (2013). Disgust: Evolved function and structure. Psychological Review, 120, 65-84. doi:10.1037/a0030778

Wagemans, F. M. A., Brandt, M. J., \& Zeelenberg, M. (in press). Disgust sensitivity is primarily associated with purity-based moral judgments. Emotion.

Zhang, Z., Zyphur, M. J., \& Preacher, K. J. (2009). Testing multilevel mediation using hierarchical linear models: Problems and solutions. Organizational Research Methods, 12, 695-719. doi: 10.1177/1094428108327450 